\title{
New Approaches to Learning for Generation $Z$
}

\author{
Joseph B. Mosca \\ Monmouth University \\ Kevin P. Curtis \\ Monmouth University \\ Paul G. Savoth \\ Monmouth University
}

The authors conducted a review of the literature to investigate how the current and future generation of college-age students learn. The authors examined how technology and learning environments effect the students' ability to learn. The rapid development and adoption of mobile communication technology has altered the way students receive and interpret information. The change in the way students learn is leading to a need for change in the way teachers should deliver curriculum to students. Using multiple inclusions of pedagogical approaches (MIOPA) the authors have been able to increase students' engagement and learning.

Keywords: MIOPA, Generation Z, Educational Technology

\section{INTRODUCTION}

The Millennial generation consists of those born between 1982 and the early '90s, while Generation Z consists of those born 1995-2012. All educators need to become aware of the learning preferences for students from these two generations. Both the Millennials and the Generation $\mathrm{Z}$ students are more technologically sophisticated and may be more self-directed than previous generations; therefore, educators need to reinforce critical thinking skills and modify their instructional approach to maximize the engagement of these students. Students have become accustomed to learning online and watching videos rather than reading textbooks. Students who have grown up with the current technology are considered digital natives, yet they lack the skills to use the technology in a strategically significant way to plan and develop a career. Educators should adopt and employ the technology students are accustomed to using and instruct them on how to utilize it to advance their thinking and strategically plan for their future career goals. The hypotheses tested in this report were a.) students preferred doing hands-on experience instead of lecturing, b.) students preferred working in groups and problem-solving, instead of working alone and completing work that required only memorization or the recall of factual information, and finally, c.) students preferred learning in a multimedia rich environment that utilized a variety of 
activities and hands-on activities to reinforce their learning. The authors designed and conducted a survey to ascertain student attitudes with regards to the stated hypotheses.

\section{A LITERATURE REVIEW OF GENERATION Z}

Previous generations were somewhat diverse, but not as diverse as Generation Z (the Z's). The Z's are accustomed to biracial, multiracial offspring, and open-minded to parents of the same sex (Pew, 2014). Shatto and Erwin (2016, p.6), point out the Z's have easy access to streaming services so they can watch programming at their convenience on a multitude of devices. They spend up to 9 hours a day on personal cell phones, making them increasingly dependent on mobile technology. Shatto and Erwin noted the inability of the Z's to analyze the validity of information and critically use the information they receive. This technology dependence has a direct, although sometimes flawed, influence on how they learned. Educators need to change their instructional approach and deliver concepts in smaller segments, considering their attention span is only 8 seconds long.

Shatto and Erwin offer some teaching tips:

- Use mobile technology when possible.

- Use assignments that can be completed on tablets or phones.

- Encourage collaboration using technology.

- Reinforce concepts with YouTube videos.

- Incorporate hands-on experiences in the classroom.

Drs. Hallowell \& Ratery (2011, p.28), refer to the short attention span as "acquired attention deficit disorder" because their brains are now wired to comprehend complex visual images. Therefore, a visual approach to teaching that includes graphics, animations or video clips is effective. While Hicks (2011) points out that even though they may appear to be inattentive and disengaged, they are "soaking up" just as much information as those who appear completely engaged. Williams (2015) contends the Z's have their eyes open and are very much aware of societal issues, mindful of the future, taking in information instantaneously and lose interest just as fast.

In some ways, the Z's are like previous generations, they rely on their electronic devises and their social skills are weaking. However, advancing technology has had a major impact on both their behavior and their thinking, which makes them different from previous generations. As a result, they possess higher confidence and self-esteem, are very much aware of trends, and are technologically adept due to their early introduction to technology and adaptation. They see themselves as bright, part of the global village, accepting of a diverse population, and concerned about environmentally safe products. They are constantly engaged in information sharing by utilizing a multitude of open platforms. Mobile devices are their preference along with media with which they can interact (Gupta, Gagan, 2014).

University professors need to consider how important it is to establish an educational environment with the clear objective of facilitating the acquisition of knowledge, skills, attitudes, and values. An optimal learning environment should foster pedagogical components that encompass information, performance, situations, and hands-on experiences along with collaborative activities with other students, which allows for the exchange of knowledge. It is the exchange of knowledge and the interactive experience, coupled with hands-on reinforcement, that results in the greatest individual learning. When students are given the opportunity to exchange knowledge among themselves, they are empowered. They feel that what they are learning is relevant to their future. Being actively engaged with the information they are acquiring will give them a comprehensive approach to learning and thinking critically-an important component for Generation Z. Currently, universities who are entrenched in the traditional model of teaching by providing most of its services face to face on a campus should consider a change. Increasingly, learning takes place outside the classroom and instructors need to adapt to physical and virtual educational environments in order to keep up with the current advances in education (Jaleniauskiene and Juceviciene, 2015). 
Preparing the current and next generation of students requires teacher preparation programs that incorporate teaching methods that students will learn from, but also enjoy. Additionally, well thought out professional development must be employed to prepare in-service educators so that they have the confidence and skills necessary to properly prepare students for their futures.

The development of our current mobile communication technology has created an artificial division between educators and students. This division has developed due to the rapid changes in technology over the last two decades. Current teaching methods have not adapted to address the ever-changing technology and its impact on student learning. When educators are uncomfortable with the use of technology, students suffer. Students learn best when they are actively engaged with the content. Utilizing technology to engage students with the content allows educators to transform their educational environment from teacher-centered to student-centered. Utilizing professional development to train teachers on effective technology practices can help teachers to better prepare their students for the future.

\section{WHAT IS LEARNING?}

Learning is the means by which humans acquire skills and knowledge, resulting in a long-term change in mental representations or associations that are the result of experiences. One can determine if learning has taken place by assessing the following:

- A new behavior has been accomplished.

- Being able to recall information, facts, and knowledge, more quickly than previously.

- Being able to view and discuss a topic with more details. (Ormrod, 2016,p.10-49),

Generation Z's are part of a knowledge society requiring radical new approaches to learning. Education needs to shift its objectives to life-long and life-wide learning because future employees will be knowledge workers who will be able to transfer learned knowledge to solve a complex problem. Knowledge is the cornerstone of technology, commercialism and cultural forces on organizations and the economy. Z's will require skills and general knowledge that is significantly different from previous generations. They will be sitting in front of monitors, holding iPads and will be emerged in information and communications (Kalantzis \& Cope, 2016).

Reviewing the criteria of learning, there are three components:

- Change cannot take place without learning.

- Over time, learning is maintained.

- Experiences provide learning. (Kalantzis and Cope, 2016, pp. 26-31).

Learning is a combination of experiences to alter behavior, which occurs through practice (Schunk, 2016), therefore, exploring the benefits of hands-on and experiential experiences should be considered when preparing to teach the $\mathrm{Z}$ generation of students, keeping in mind that they are visual and prefer physical learning applications and engagement (Kalantzis and Cope, 2016). With the advent of the information age, we have begun a new economic paradigm with knowledge as its primary commodity. The next generations will be working in what is being called the "Knowledge Economy" in which knowledge will be used to generate tangible and intangible values.

Future educators need to play a role in developing their students' creative, productive and social potential. A reconceptualization of the three R's needs to be considered if contemporary changes to learning are to take place, whereby the new learning will be general in its focus, rather than targeting a particular need or use. Future students will be capable of adjusting to and causing change, problem solve, collaborate, and comprehend diversity. That said, learning will be increasingly interdisciplinary, resulting in an intensified engagement with general knowledge, resulting in lifelong and life-wide learning. All those currently teaching must review the components of formal learning:

Kalantzis and Cope, (2016) stated that formal learning must be:

- Deliberate and explicit

- Structured and goal oriented

- Analytical, abstracting, and generalizing (Kalantzis and Cope, (2016, p 26-30) 
As Figure 1 illustrates, the learner is engaged in an organic environment where a concept or topic can be considered from many points of view. Having multiple perspectives empowers the students' freedom to explore a variety of avenues, actively challenging the student to become part of the learning process. Students do not all learn the same way; however, when teachers vary the learning environment and offer multiple choices for students to demonstrate their understanding of a concept, a higher percentage of students will master the information. Active learning can be defined as "a combination of teaching approaches, environment, and technology, which supports learning that is student-centered to motivate students to take part in the learning process" (eCampus News, 2017). For the purpose of this study, active learning classroom will be referred to as "MIOPA," multiple inclusions of pedagogical approaches, which are a configuration of various pedagogical approaches to instill collaboration, problem solving, exercises such as hands-on experiences, creativity, the value of inquiry learning and the development of the learner's confidence.

FIGURE 1

\section{GRAPHIC APPROACH TO INFORMAL LEARNING}

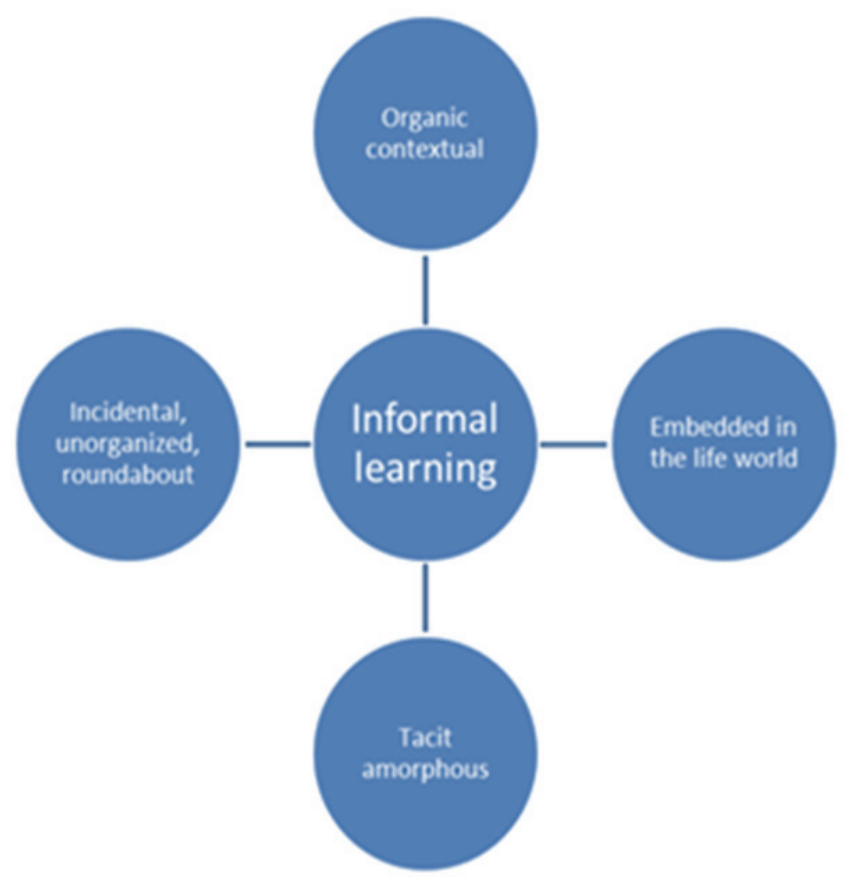

According to Aurel Pera (2013), multimedia classrooms can promote a meaningful learning environment by varying both the number of representations students are exposed to and the degree of their engagement in the learning process. Interactivity is becoming a preferred method for learner success. Students learn better when provided with learning environments that combine verbal, visual, interactivity, empowerment, and hands-on experiences for more intense cognitive engagement. Pera concluded that there is a positive relationship between higher education environments when instructors employed active and collaborative learning techniques. As stated above and illustrated in Figure 2, the MIOPA approach makes room for considering a multiple-pronged approach to enhance student engagement for intense cognitive learning. 
FIGURE 2

\section{ILLUSTRATION IF MIOPA}

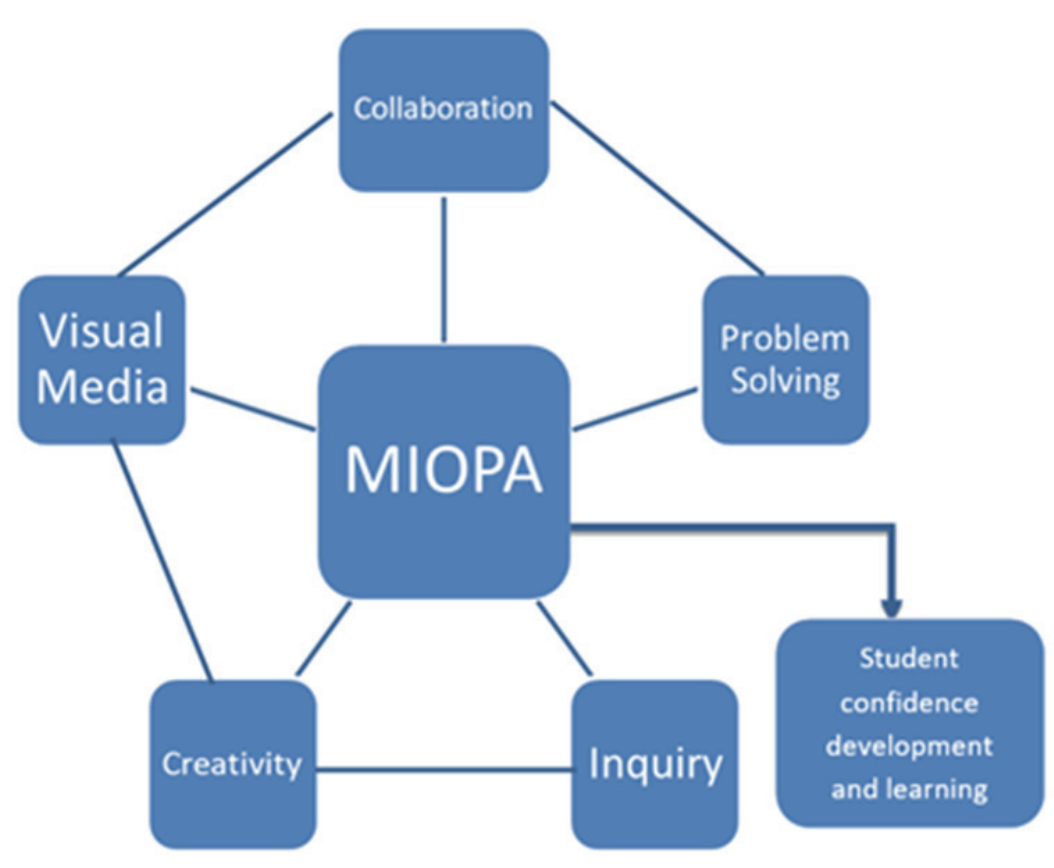

The Faculty Survey of Student Engagement (FSSE), administered to 14,512 faculty members in 2016 by The Indiana University Center for Postsecondary Research, asked faculty to what extent they structured courses to achieve various objectives. Ninety-three percent responded that they "very much" or "quite a bit" structure their courses to improve critical thinking. The other primary objectives identified by sixty-four to sixty-seven percent of respondents included writing clearly, acquiring a job or work-related knowledge and skills, working effectively with others and solving complex real-world problems. These goals are consistent with the discussion of the need for a MIOPA approach that is focused on student engagement.

Question 24 of the survey asked faculty the percentage of time in class that was spent lecturing, discussing issues, in small group activities, presentations, videos, independent student work, and testing. Thirty-one percent of respondents indicated they spend over fifty percent of class time lecturing. Twenty-seven percent spent thirty to forty-nine percent of the time lecturing. Seventy-two percent of faculty spent less than thirty percent of classroom time for discussion, and sixty-seven percent spent less than twenty percent of classroom time in small group activities. The data raises the question of whether there is adequate student engagement to accomplish the identified objectives.

The related National Survey of Student Engagement (NSSE), also administered nationally by Indiana University to an extensive body of students, does indicate that eighty-five percent of students believed that they "very much" or "quite a bit" learned to think critically; however, only about twothirds of the students agreed that they acquired work-related knowledge and skills or were better able to solve complex or real-world problems. This result also raised the question of whether there was sufficient student engagement in the classroom.

The survey also indicated that there was a gap between the time faculty expected students to prepare for class and the actual time students spent studying. Fifty-two percent of faculty expected students to spend five to 10 hours per week preparing for their class; however, only eleven percent of the faculty actually believed that students spent that much time studying. This is consistent with student reported data on the time spent preparing for class. There are some studies indicating that student preparation time has decreased since 1960. A MIOPA approach may improve student 
preparation because there is a direct connection between preparation and required participation and engagement in class.

Educators spend hours planning learning experiences for their students, but students may not engage enthusiastically. One of the biggest frustrations for educators is unmotivated students. One way to address this problem is through student empowerment. Instructors all have a genuine interest in their students' success. Empowering students may increase their engagement and therefore, their learning. Empowerment is accomplished by allowing the student to put forth their own ideas in correlation with the concepts put forth, set their own schedules for study and providing an opportunity to discuss with each other what they are doing and sharing the learning. As a result of student empowerment, it becomes the process of energizing others in order to help them experience the task they are engaged in as empowering. By considering the employment of student empowerment, the result is intrinsic task motivation (Sanders, Boss, Boss, Mc Conki, 2009).

When preparing a lesson plan to engage students in the learning process, instructors need to create learning spaces that foster a student-centered environment. For the most part, the traditional classroom setting with seats/desks/tablets in a fixed lined up position facing the instructor at the front of the room does not give rise to student empowerment or an engaging environment. Learning effectiveness increases when the learning environment is created for a variety of settings (David Kolb, 2015). As Kolb suggests, the authors designed a lesson plan implementing a hybrid instructional approach as indicated in Figure 3.

The images in Figure 3 are display examples of how these concepts can be applied to starting a business, a science project, designing a product, practicing a new Math concept, etc. The objective is for students to be given an opportunity to take an active part in using the material they have been exposed to in the online session. In addition, students will be empowered to control their group activities, decide how they will demonstrate to the class what was learned by combining what was learned from the online lesson, group discussion, and interaction with other groups. It is not suggested here that these examples are the only way to engage students in the learning process. These examples are just the beginning of suggestions to consider when planning lessons for generation Z. According to Winsett, Foster, Dearing and Burch (2016), students should be given the opportunity to engage in a variety of approaches such as collaborating with others in the classroom, outside the classroom, and to be affectively and physically involved in the learning to comprehend new concepts. These methods provide more time for students to be exposed to a concept and a chance to practice.

FIGURE 3

\section{STUDENT ENGAGEMENT SPACE}

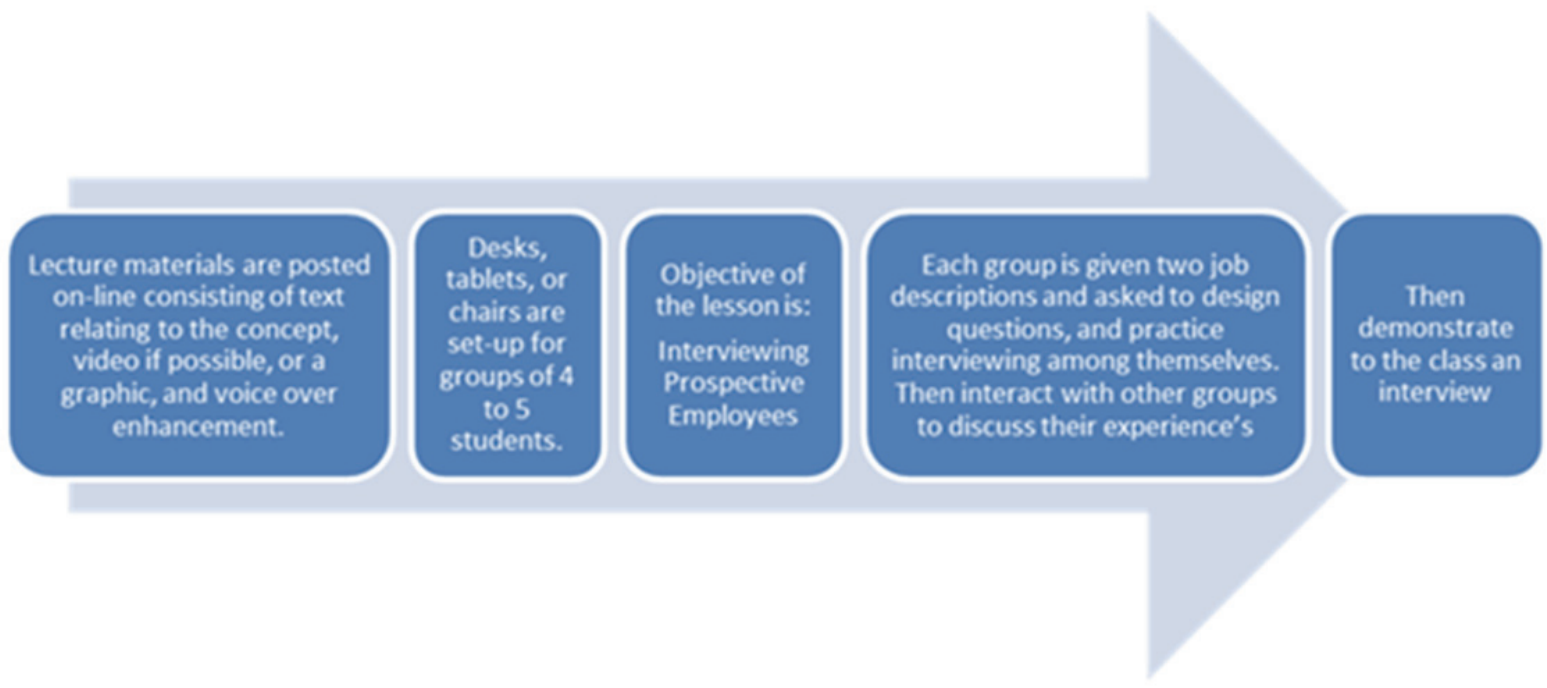




\section{METHODS}

The authors developed an eleven-question survey to ascertain students' preferences with regards to lecture, hands-on-learning, problem-solving, group-work, informal learning, use of multimedia in the classroom, and diversity of teaching methods in the classroom. The survey was distributed to a diverse group of students including graduate and undergraduates at Monmouth University. Graduate students were included in the study to discover if their attitudes toward learning were different then undergraduate students, as the graduate students have already entered the workforce and had experienced a traditional undergraduate education. The student population in the study was comprised of majors from the General Business, Communication, Healthcare, Criminal Justice, Accounting, Finance, and Marketing programs. One-hundred and thirty-three students were surveyed over two semesters during the fall 2018 and spring 2019 semesters at Monmouth University.

\section{RESULTS}

Data was collected through an anonymous student survey. The survey consisted of 11 questions inquiring about student preferences conserving various aspects of the of course delivery and teaching methods. The results are tabulated and graphically represented below in Table 1 and Figure 4.

TABLE 1

MIOPA STUDENT SURVEY RESULTS

\begin{tabular}{|l|r|r|}
\hline MIOPA Survey Results & Yes & \multicolumn{1}{l|}{ No } \\
\hline I feel I learn more by "doing" than be lectured to? & $96.2 \%$ & $3.8 \%$ \\
\hline Instructor used class time effectively? & $97.7 \%$ & $2.3 \%$ \\
\hline Case analysis is a real-world learning process? & $100.0 \%$ & $0.0 \%$ \\
\hline Class time passes quickly when students are engaged in learning? & $99.2 \%$ & $0.8 \%$ \\
\hline Videos help to bring in real-world situations? & $97.7 \%$ & $2.3 \%$ \\
\hline Students working in groups completes the problem-solving process? & $98.5 \%$ & $1.5 \%$ \\
\hline Do you learn in the environment? & $99.2 \%$ & $0.8 \%$ \\
\hline Is this knowledge usable in the workplace? & $98.5 \%$ & $1.5 \%$ \\
\hline Do you prefer learning experiences over lecture? & $96.9 \%$ & $3.1 \%$ \\
\hline Would you recommend this instructor to a friend? & $98.5 \%$ & $1.5 \%$ \\
\hline Does this learning environment help you overall? & $97.7 \%$ & $2.3 \%$ \\
\hline
\end{tabular}




\section{FIGURE 4 \\ MIOPA STUDENT SURVEY RESULTS}

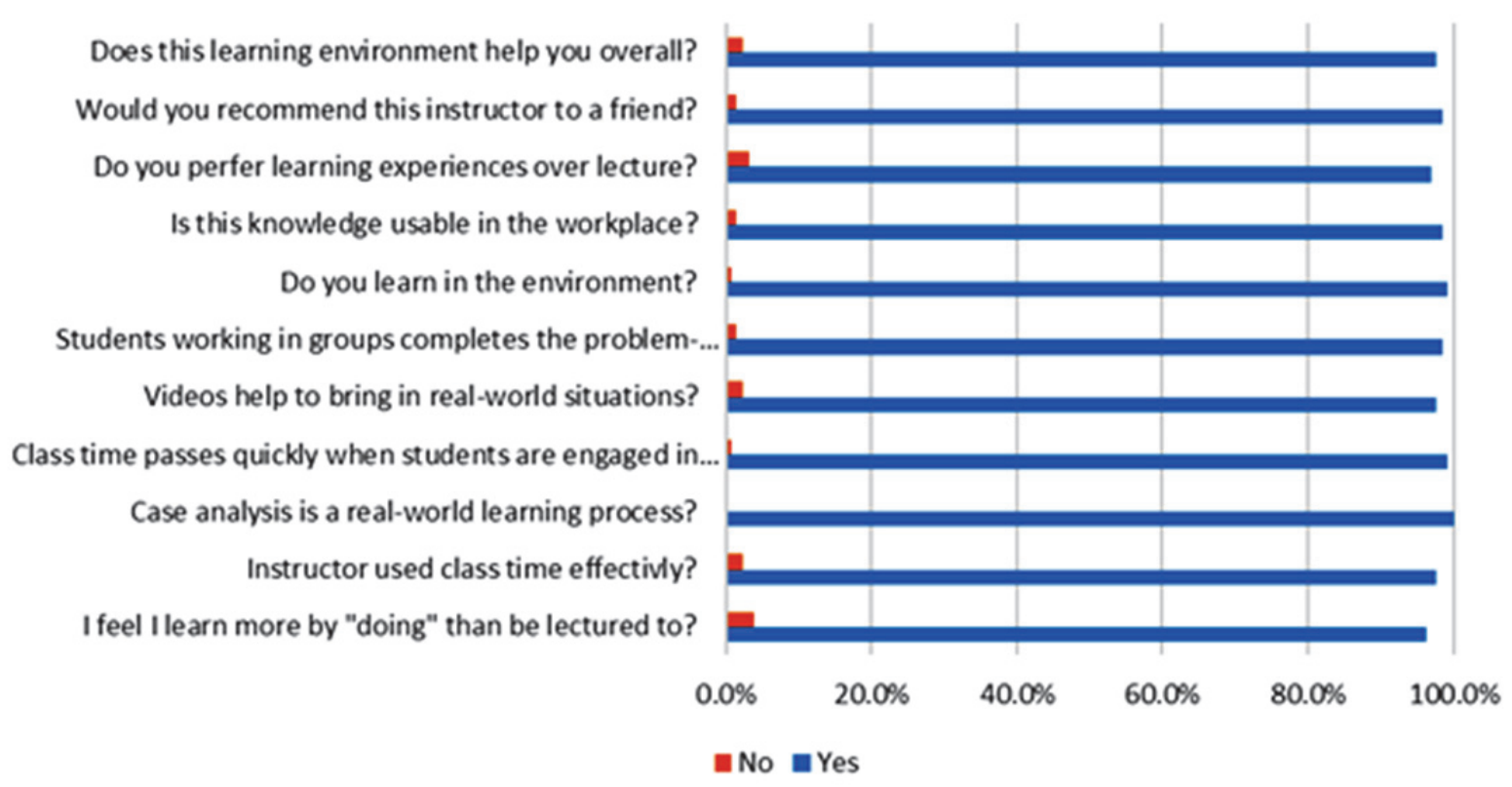

\section{CONCLUSIONS}

Those in higher education can observe students at the junior high school levels to get a glimpse of their behavior and what teaching approaches might be best suited to their lifestyle, their exposure to technology, and their reliance on social learning. This study highlighted the importance of instructors embracing an approach that teaches students that learning takes place through the instructor empowering the student to engage in the learning. In addition, the study found that instructors benefit from using more than one instructional approach. As this study indicates, students want to be actively engaged in the learning and benefit when instructors provide space for students to flexibly interact with others who are also allowed to problem-solve on their own. The authors put forth some suggested methods that combine a variety of approaches that could keep the $\mathrm{Z}$ generation students engaged considering their limited attention span. As stated, these are not the only possible approaches, but methods to consider when the future generations become our students, for as most educators know, each student generation has their own view of the environment and where they fit into it.

The authors of this article acknowledge that a major limitation of this article is the lack of empirical data to back up their assertions. In the future, these authors will attempt to validate the statements put forth in this article by developing and conducting a survey instrument to collect data from a broader student population.

The ideas put forth in this paper are to consider providing a creative space in which students can interact and engage with real world problems, allowing them to collaborate among themselves and then practice the newly learned concept. This seems to coincide with the maxim "Seeing is believing, engaging and practicing is learning."

In 1798, the romantic poet, Friedrich Schlegel, understood that developments did not simply go from one point to another and then stop, but that they were an ongoing process. Likewise, educational methods and technological development are never stagnant and should not be treated as such. Educators need to be kept abreast of the developments in current educational methodology and technology and their application in the college classroom. 


\section{REFERENCES}

Gupta, O., \& Gulati, G. (2014, August). Psycho-analysis of Mobile applications usage among Generation $\mathrm{Z}$ Teens. International Journal on Global Business Management \& Research, 3(1), 80-95.

Hallowell, E., \& Ratery, J. (2010). Driven to Distraction. Anchor Books, New York.

Hicks, S. D. (2011, August). Technology in today's classroom: Are you a tech-savvy teacher? The Clearing House, 84(5), 188-191. doi:10.1080/00098655.2011.557406

Jaleniauskiene, E., \& Juceviciene, P. (n.d.). Reconsidering University Educational Environment for Learners of Generation Z. KTU, Social Science, 2(88).

Kalantzis, M., \& Cope, B. (2016). Learning By Design. Common Ground Publishing, LB10273K35(2014). ISBN 978-1-61229-468-1, 26, 27, 30, 31, 192, 193.

Kolb, D. (2015). Experiential Learning: Experience as the Source of Learning and Development, $2^{\text {nd }}$ E. Pearson Education. ISBN 13: 078-0-13-389240-6, pp 294-296.

Kuh, G.D. (n.d.). National survey of student engagement; the college student report. Bloomington, IN; Indiana University Center for Postsecondary Research and Planning.

Ormrod, J. (2016). Human Learning, $7^{\text {th }}$ E. Always Learning, Pearson, New York, pp. 10, 49. ISBN 100-13-357928-X.

Pera, A. (2014). The Relationship Between Faculty Practices And Student Engagement and Learning. Analysis and Metaphysics, 12(2013), 160-165. ISSN 1584-8574.

Pew Research Center (2014). Millennials in Adulthood. Detached from institutions, networked with friends. Retrieved from http://www.pewsocialtrends.org/2014

Sanders, M., Boss, A., \& Mcconkie. (2009). Increasing Student Engagement and Learning: Using Big Hairy Audacious Goals As An Empowering Semester Project. Academy of Management, Chicago, 495,496, 498.

Schunk, D. (2016). Learning Theories: An Educational Perspective, $7^{\text {th }}$-E. Always Learning, Pearson, New York. ISBN-10-0-13-359972-8.

Shatto, B., \& Erwin, K. (2016). Moving On From Millennials: Preparing for Generation Z. Journal of Continuing Education in Nursing, 47(6).

The K-20 Active Learning Landscape (2017). eClassroom News, pp. 1-8. Retrieved February 25, 2017, from eCampusnews.com/pdfs/k-20-active-learning-landscape

Williams, A. (2015). Move Over Millennials: Here Comes Generation Z. New York Times, 9/20/2015, $3 p p$.

Winsett, C., Foster, C., Dearing, J., \& Burch, G. (2016). The Impact of Group Experiential Learning on Student Engagement. Academy of Business Research Journal, Gulfport, 3, 7-17. 